\title{
NEM CRIADORES, NEM CRIATURAS: ÉRAMOS TODOS DEVIRES NA PRODUÇÃO DE DIFERENTES SABERES
}

\author{
Eduardo Antonio de Pontes Costa \\ Cecília Maria Bouças Coimbra \\ Universidade Federal Fluminense, Niterói, Brasil
}

\begin{abstract}
RESUMO: O presente trabalho fala de um relato sobre os jovens pobres inscritos em uma experiência de formação profissional em uma unidade militar no Rio de Janeiro. Pretendemos apontar como a instauração de uma pesquisa em devir, implicada com outro modo de conhecer, era a expressão das rupturas, das intensidades, dos atravessamentos, da recusa à neutralidade, sobre o saber e o fazer da psicologia e da educação, e que nos constituía no instante da pesquisa. Tomamos, como referente na produção de um modo sensível de pesquisar, alguns conceitos-ferramentas da Análise Institucional, fundamentais para pôr em análise este estabelecimento militar que atravessa e produz um "modo-jovem-trabalhador". Destacamos, expressivamente, que a produção de conhecimento se deu no momento em que tentávamos desconstruir saberes e práticas que os jovens experimentavam no projeto, objetivando potencializar sentidos múltiplos, diversos, a partir do diálogo, da experiência e dos encontros potentes com eles. $\mathrm{O}$ diário de campo, uma das ferramentas da Análise Institucional, ao traduzir o cotidiano denso trazido pelos jovens, nos permitiu o registro de memória sobre tantas vidas, não apenas a nossa, também a dos educadores e a dos responsáveis pelo projeto.
\end{abstract}

PALAVRAS-CHAVE: Pesquisador; implicação; devir.

\section{NOR CREATORS, NOR CREATURES: WE WERE BECOMING IN THE PRODUCTION OF DIFFERENT KNOWLEDGES}

\begin{abstract}
The present work discusses a report on poor youngsters registered in a vocational training experience at a military unit in Rio de Janeiro. We intend to show how the instauration of a research, implied with another manner of knowing, was the expression of ruptures, intensities, de-centering, refusal of neutrality, about the knowing and making of psychology and education, and which constituted us as the research was carried out. As reference in the production of a sensitive way of doing research, we use some concept-tools from Institutional Analysis to analyze this military academy that de-centralizes and produces "young-worker-mode". Highlighting, expressively, that the production of knowledge occurred when we attempted to deconstruct knowledge and practices which the youngsters experimented in the project, aimed to potentialize multiple and diverse meanings, on the basis of dialogue, experience and the potent meetings we had with them. The field notebook, one of Institutional Analysis' tools, by registering the dense daily life of youngsters, enabled us to record the memory of so many lives, not only ours, but of the educators too and of those in charge of the project.
\end{abstract}

KEYWORDS: Researcher; implication; becoming.

O meu olhar é nítido como um girassol. Tenho o costume de andar pelas estradas olhando para a direita e para a esquerda, e de vez em quando olhando para trás... E o que vejo a cada momento é aquilo que nunca antes eu tinha. . . Sinto-me nascido a cada momento para a eterna novidade do Mundo...

Fernando Pessoa
Trata-se o presente artigo de parte de pesquisa de doutorado ${ }^{1}$ apresentada ao Programa de Pós-Graduação em Educação da Universidade Federal Fluminense, em março de 2007. Nesse trabalho, os autores, ao relatarem um modo de pesquisar sobre a produção de um "modojovem-trabalhador", expressam os desafios e as intensidades que atravessaram os encontros com os jovens. Situam, inclusive, a escolha teórico-metodológica até os 
desdobramentos sobre os encontros potentes com os jovens, em que um modo sensível de produzir saberes, diante de diferentes subjetividades, nos apontavam para vidas em sua multiplicidade.

\section{A pesquisa como desvio na produção de sentidos}

Dessacralizar "verdades" não é tarefa fácil. O "olhar da ciência" eterniza a razão, produzida e cultuada desde, em especial, o mundo grego. Ao longo da história, fomos subordinados à razão, pelo menos, desde Platão, que partia da premissa de uma existência das idéias eternas e perfeitas, em que a educação deveria conformar modelos racionais de formação humana, de acordo com os papéis sociais a serem cumpridos na polis. Almas de ouro, prata e bronze para dirigir, guerrear e servir ao Estado. Assim, somente a razão poderia ter o perfeito conhecimento do "ser", forjado por categorias universais, pelos dualismos universalizantes (Collinson, 2004). A educação teria uma importância para conduzir alguém à excelência ou à virtude. Acreditava-se, inclusive, que as melhores "almas" deveriam ser encaminhadas corretamente. Na Modernidade, a valorização do método científico e a difusão do pensamento empirista marcaram um novo olhar sobre a produção histórica do conhecimento. Com Francis Bacon (1561-1626), o discurso da ciência moderna inaugurou um conhecimento fundado na observação, em que o discurso científico faria do homem o "senhor e o possuidor da natureza" (apud Santos, 1999).

A partir de René Descartes (1596-1650), a dualidade da vida se inscreveu em um homem que separa a si próprio do objeto a ser observado, ao difundir a idéia de que existia uma verdade no mundo da natureza.

... Percebi, então, que a verdade, penso, logo existo, era tão sólida e tão exata que sequer as mais extravagantes suposições dos céticos conseguiriam abalá-la ... não deveria ter escrúpulo em aceitá-la como sendo o primeiro princípio da filosofia ... (Descartes, 1975, p. 44).

Reconhecendo-se no direito de compreender a verdade do mundo ao iluminá-lo com a própria racionalidade, Descartes faz da ciência, paradoxalmente, ao produzir uma "forma-indivíduo", ferramenta de expressiva cisão homem x experiência. Ao negar as multiplicidades e as formas fragmentárias com que a subjetividade é produzida no social (Deleuze \& Guatarri, 1992), ao buscar uma verdade primeira, o referido autor estabeleceu um ideal matemático na medida que “...cria uma fantasia unitária e centralizadora que reduz o conhecimento do mundo àquilo que se revela à consciência de seu pretenso "senhor" (Paulon, 2005, p. 21).

Esse mesmo homem, considerado livre de questionamentos políticos, sociais, por exemplo, passa- ria a fundar a certeza de uma suposta neutralidade científica, produzindo, certamente, um sentido de ação do pesquisador em relação ao objeto pesquisado. Nesse discurso universalizante e forjado pela modernidade, é como se o tempo fosse incorporado a uma entidade cronológica, a uma história contínua, que se cristalizaria em um presente vivido, pois o que é verdade “... permanece verdade, assim reza o princípio de identidade, princípio fundamental da coerência e do pensamento, axioma primordial da metafísica, filosofia que se define como busca de uma verdade permanente" (Lins, 2001, p. 106).

Nessa esteira de um sujeito metafísico, parece-nos que a regularidade do pensar atrela-se a uma razão em que não mais é possível afirmar uma nova experiência de vida. No presente trabalho, refutamos esse olhar e reafirmamos outra concepção de experiência. Experiência que nos permite perceber que outras formas de leituras da realidade, de concepção de homem e de mundo, podem ser construídas no presente, um presente entendido em permanente dilatação, na medida que experimentar é da ordem do devir-pensamento, pois o pensar: “. . . é sempre experimentar, não interpretar, mas experimentar, e a experimentação é sempre o atual, o nascente, o novo, o que está em vias de se fazer" (Deleuze, 1992, p. 132). Nesse movimento de inventare reinventar um modo de pesquisar:

Hoje começo a redigir meu diário de campo sobre as minhas primeiras entradas e trajetórias que irão compor o meu perder-me e reencontrar-me constantes nesse trabalho de doutoramento. Quero poder me multiplicar na diversidade da vida, para que eu possa ver o mundo sob diferentes ângulos, como tentou fazê-lo, numa outra perspectiva, o poeta Fernando Pessoa. (Diário de Campo, 10/09/2003).

Não buscamos nessa pesquisa o "eterno", como diz Deleuze (1992) valendo-se de Foucault, ainda que fosse a eternidade do tempo, mas a análise sobre a emergência de uma prática de formação profissional que se atualiza na vida de parte de uma juventude pobre. Nessa perspectiva, acreditamos que, ao romper com o tempo cronológico, poderíamos colocar as nossas vidas em uma não-montagem de acontecimentos do passado, selecionados e organizados. Assim como Walter Benjamin (1994), rejeitamos a repetição do passado pela criação do futuro, a partir do presente. Talvez, sejamos como um ponto em movimento. Algo que escapa, que guarda em si o poder da criação, que respira e produz potência, que se refaz a todo momento. Entendemos que esse poder da criação se faz presente, em especial, no olhar crítico da juventude que contesta e tenta subverter as "coisas" do mundo, com uma linguagem possuidora de uma visão utópica e transformadora da história. Acontecimentos esses que atravessam e constituem o presente trabalho e que são evidenciados por fragmentos do nosso diário de campo, ao focarmos os jovens em uma experiência 
profissionalizante desenvolvida por um estabelecimento do terceiro setor, em uma unidade do Exército.

Nesse contexto, passamos a interpelar as teorias totalizantes, as verdades que atravessam e constituem práticas e sujeitos, seus regimes de verdades que se forjam nas organizações e nas relações sócio-institucionais, diante de uma realidade complexa e múltipla que nos constitui. Por regimes de verdade, entendemos as normas e regras produzidas pelas práticas sociais, como o Bem e o Mal, definindo, assim, a "normalização" da vida na sociedade (Foucault, 1974). Propomo-nos a buscar uma concepção de homem que represente outras formas de construção de conhecimento ao colocar em xeque a noção de neutralidade na produção científica tão presente nas ciências da objetividade, e acolhidas pelas ciências humanas e sociais. Questionando o estatuto de neutralidade nas ciências, Hilton Japiassu (1975) afirma que, se examinarmos em sua atividade real, em suas condições concretas de trabalho, vemos que a "razão" científica não é imutável. Ela muda. É histórica. Ele conclui que:

... não há ciência 'pura', 'autônoma' e 'neutra', como se fosse possível gozar do privilégio de não se sabe que 'imaculada concepção'. Espontaneamente, somos levados a crer que o cientista é um indivíduo cujo saber é inteiramente racional e objetivo, isento não somente das perturbações da subjetividade pessoal, mas também das influências sociais. (Japiassu, 1975, p. 9).

Propomos, então, problematizar as cristalizações que nos atravessam e constituem como sujeitos dos especialismos, formados pelos discursos universalizantes e pretensamente únicos pautados nas especializações que isolam os profissionais e fragmentam seus trabalhos. Não pretendemos discutir os aspectos "quali-quanti" na produção de conhecimento. Entendemos a pesquisa como produção histórica e social. Sendo histórica, há o envolvimento de diferentes saberes, olhares, opiniões, crenças. Há uma produção de conhecimento que se processa no movimento da vida, no encontro da vida que se produz em seu imediato, pela surpresa, pelos afetos, na reinvenção de nós mesmos, como nos diria Paulo Freire (1998). Tomados pela surpresa dos encontros:

Passei na sala de aula, então, para conhecer os jovens. Todos estavam me aguardando. Sabiam da presença de uma figura que estava ali para conhecê-los. Havia na sala algo em torno de trinta e cinco jovens: negros e mestiços. Me apresento, confesso, com um certo nervosismo. Sou tímido e isso me prejudica bastante. Tenho consciência desse meu traço. Para vencer cada momento de timidez, só mesmo enfrentando-a. Às vezes tenho a impressão de que pensamento e linguagem não estabelecem uma boa conexão com as minhas palavras. Bem, de qualquer forma, falei um pouco do meu trabalho. Claro, numa lingua- gem mais próxima possível para o entendimento de todos. Usei de poucos exemplos para ilustrar o que venho desenvolvendo. Acredito que todos entenderam, até porque fiz algumas perguntas para os jovens. As respostas foram o alento para acreditar que eles de fato entendiam o que eu falava. $\mathrm{O}$ capitão, o tenente e o educador me acompanharam até onde estavam os jovens. Inclusive, ambos, capitão e tenente afirmaram diante de todos que o espaço militar do projeto com jovens pobres estaria à minha disposição para qualquer atividade que eu pretendesse desenvolver, caso eu assim o desejasse. Mais uma vez agradeci pela abertura de um possível campo de trabalho para o desenvolvimento da minha pesquisa. (Diário de Campo, 24/03/2004).

Entre alguns aspectos importantes que nortearam esta pesquisa, um deles diz respeito à noção de neutralidade e de objetividade do pesquisador. Não assumíamos uma postura de afastamento, de isolamento, mas de aproximação a um estabelecimento de natureza profissionalizante. Colocávamos em tensão aquilo que nos constituía como psicólogos e pesquisadores. Tensão e transversalização entre macro e micro política norteavam nossas análises. Rejeitávamos o lugar historicamente produzido e destinado aos sujeitos da psicologia e também da educação. Segundo afirmam Deleuze e Parnet (1998), indivíduos e grupos são atravessados por linhas de diversas naturezas. A primeira seria a de segmentaridade dura, constituída pela família, pelo trabalho, pela profissão, pela escola, pelo Estado, dentre outras. Mas, também, existem as linhas flexíveis, em certa medida, moleculares. São os pequenos desvios, os micro-devires. Além dessas duas, há as chamadas linhas de fuga ou de ruptura que, segundo Deleuze e Parnet (1998, p. 162) podem “ ... virar linhas de abolição, de destruição, dos outros e de si mesma". O grande desafio, conforme esses autores, é como traçar linhas de fuga que possam desarmar estas armadilhas.

Assim, colocar em análise algumas das linhas duras - da instituição formação - em especial da psicologia e da educação, é promover desvios de um ofício, de um saber, que nos constitui em sujeitos dos "especialismos". Portanto, nessa perspectiva, está em análise, certamente, o lugar e o fazer da psicologia e da educação, no sentido de as duas poderem se submeter aos especialismos ou ir além de traduzi-los na sua dimensão teórico-prática. $\mathrm{O}$ ato de ensinar, também, pode cair nessa armadilha e confirmar esse olhar funcionalista, conforme as significações dominantes, como bem nos afirma Parnet (apud Deleuze \& Parnet, 1998, p. 28) sobre a relação professor-aluno, em que, especificamente, quando:

... a professora explica uma operação às crianças, ou quando ela lhes ensina a sintaxe, ela não lhes dá, propriamente falando, informações, comunica-lhes comandos, transmite-lhes palavras de ordem, ela faz 
com que produzam enunciados corretos, idéias 'justas'...

\section{Potentes dispositivos, potentes produções}

Ao ampliarmos e ao colocarmos em análise aquilo que nos atravessa e nos constitui, sujeitos dententores de palavras de ordem, destacamos alguns conceitos-ferramentas da Análise Institucional fundamentais, também, para pôr em análise este estabelecimento de formação profissional que atravessa e produz um "modo-jovem-trabalhador”. A pesquisa-intervenção, por sua dimensão crítica e implicada no instante da pesquisa, a partir do dispositivoencontro, em que o pesquisador e o pesquisado, sujeito e "objeto" do conhecimento, se constituem no mesmo tempo. A implicação - recusa da neutralidade do pesquisador em que a análise não consiste apenas em analisar o outro, mas em analisar a si mesmo. E o diário de campo - recurso metodológico revelador da nossa condição de pesquisador e que traduz o universo intenso e denso dos vários caminhos percorridos pela pesquisa. Sobre os conceitos e concordamos com Gilles Deleuze (1990) - ele propõe que sejam como uma caixa de ferramentas que as utilizemos desde que sirvam, que funcionem, que nos potencializem. Dentro desta perspectiva, o nosso estudo não se pretende produtor de pretensas verdades, mas busca pensar outras formas de leitura da realidade a partir de conceitos que nos auxiliem a questionar e a dessacralizar determinadas práticas sociais.

Complementar aos meus futuros registros em diário de campo, penso na articulação de mais um instrumento metodológico - a pesquisa-intervenção -, ambos sensivelmente sugeridos pela profa. Cecília Coimbra, e acolhidos nas minhas 'descontínuas' e constantes entradas no campo empírico pois, se não há um caminho real para aquiescer à 'verdade', todos devem ser tentados e sentidos. (Diário de Campo, 10/09/2003).

Em linhas gerais, a Análise Institucional busca, ao opor-se à lógica identitária das "ciências da objetividade", desarticular práticas e discursos instituídos. Segundo Coimbra (1995, p. 66), tal análise: “... vai nos falar do intelectual implicado ... Portanto, analisa-se [sic] ... os diferentes lugares que se ocupa no cotidiano e em outros locais da vida profissional; em suma, na história ..."

A corrente da Análise Institucional, pensada e desenvolvida a partir dos anos de 1960 e 1970 na França, além de afetar estudiosos e intelectuais na América Latina na década de 1980, possibilitará a produção de uma pesquisa que passa a interrogar os múltiplos lugares e sentidos cristalizados pelas práticas sociais nas instituições (Coimbra, 1995; Lourau, 1993).

A noção de pesquisa-intervenção está associada à construção de analisadores, conceito-ferramenta formula- do no percurso do institucionalismo francês, que funcionam como catalizadores de sentido, desnaturalizando o existente e suas condições e realizando a análise. Éramos e funcionávamos como catalizadores, analisadores. Além desse aspecto, e nas trajetórias de intenso desejo nômade, passamos a perceber que os conceitos são como intensidades (Deleuze, 1992), algo que se move diante do que nos parece imóvel. Nessa busca por outros "saberes" e "sabores", Michel Foucault, Gilles Deleuze, Félix Guattari, Walter Benjamin representaram outras possibilidades de leitura diante de um mundo produzido pelo homem, onde as "verdades" desejam ser eternas e uma suposta "linha da história" tem a pretensão de infinita. Como se pudéssemos aprisionar outras dimensões da vida, do corpo, como a emoção, a intuição, a sensibilidade, a intensidade dos afetos, o desejo. O termo "afeto" neste trabalho refere-se ao sentido posto por Espinosa, ou seja, como sinônimo de "paixão". Todo corpo, todo ser existente tem o poder de afetar e de ser afetado por outros corpos ou seres (Pelbart, 2003). Atravessados por esta afetação:

Venho há dias pensando comigo mesmo como poderia ser desenvolvido um trabalho junto com os jovens. Nesses momentos, a angústia tem sido a companheira das minhas preocupações. Deparar-me com um projeto novo não é tarefa fácil. Esse enfrentamento com o novo produz uma angústia de não saber, uma ansiedade, um desamparo, um desassossego. Será que conseguirei a aprovação dos coordenadores para a realização do meu trabalho de pesquisa? . . . A definição do local é importante para o desenvolvimento do trabalho, mas até chegar lá, acredito que seja mais complicado. Há uma série de fatores que convergem a favor e contra diante desse perfil de trabalho. Não sou apenas eu que observo, sinto, percebo. Mas uma convergência de sujeitos com sensações diferentes, outras percepções, outros movimentos de vida, outros saberes, outros conhecimentos que, sendo o resultado da confrontação, da tensão, podem me fazer perceber que estou em algum lugar desse movimento. (Diário de Campo, 05/05/2004).

Como a nossa pesquisa afirmava a recusa da neutralidade e da objetividade, e como ela não transitava em torno da validação estatística, do rigor e do controle de variáveis, é necessário situar um certo diálogo estabelecido entre Deleuze e Foucault (1990) sobre o lugar do intelectual, supostamente o nosso, na produção da ciência, onde Foucault (1990, p. 71) considera que o papel do intelectual não é mais o de:

... se colocar 'um pouco na frente ou um pouco de lado', para dizer a muda verdade de todos; é antes o de lutar contra as formas de poder exatamente onde ele é, ao mesmo tempo, o objeto e o instrumento: na ordem do saber, da 'verdade', da 'consciência', do discurso. 
Como já mencionado, Foucault (1974) assinala que a verdade é produzida historicamente de diferentes maneiras. Em relação à ciência, Roberto Machado (1981, p. 20) afirma que ela é "...essencialmente discurso, um conjunto de proposições articuladas sistematicamente. Mas além disso, é um tipo específico de discurso: é um discurso que tem a pretensão de verdade". Segundo Michel Foucault, há nas práticas sociais a produção de duas histórias da verdade. Uma produzida pela ciência, como o autor bem afirma: “....a história da verdade tal como se faz na ou a partir da história das ciências" (Foucault, 1974, p. 8). Por outro lado, há em nossas sociedades vários lugares onde a verdade se produz, se forma, onde certas formas de subjetividades são inventadas, em específico, a subjetividade de um corpo juvenil sendo produzido por uma prática de formação profissional. Corpo juvenil que, ao se transformar em verdade, passa a ser considerado como uma instituição.

Entretanto, sobre a noção de instituição, nos ancoramos em René Lourau (1993) ao afirmar que a mesma não é uma coisa observável, mas uma dinâmica construída na e pela história, ou tempo, pois “... o tempo, o social-histórico, é sempre primordial, pois tomamos instituição como dinamismo, movimento; jamais como imobilidade. Até instituições como Igreja e Exército estão sempre em movimento, mesmo que não tenhamos essa impressão" (Lourau, 1993, p. 11). É oportuno destacar aqui que entendemos instituição como um devir permanente, que não se identificando ao de estabelecimento, ganha uma direção dinâmica, produtora de significados e sentidos históricos.

Ao produzir ciência, concebemos o pesquisador não como um sujeito que produz um saber neutro, à margem de questionamentos sociais e políticos sobre os fins de sua pesquisa. Sobre o papel do pesquisador, do intelectual, da sua implicação na produção de conhecimento, é expressiva uma afirmação de Guattari (2003, p. 24): "Chernobyl e a Aids nos revelaram brutalmente os limites dos poderes técnico-científicos da humanidade e as 'marchas à ré' que a 'natureza' nos pode reservar ...". Fazer pesquisa significa subverter os lugares tradicionalmente ocupados pelo pesquisador e pelo objeto a ser pesquisado (Coimbra \& Neves, 2002). O conceito de implicação, dispositivo trabalhado pelos analisadores institucionais, não se constitui em uma decisão consciente de ligar-se ao processo de trabalho. A noção de implicação reafirma e recusa a neutralidade do pesquisador, na medida em que há sempre uma implicação política, social e histórica que nos permite questionar o lugar que ocupamos na divisão social do trabalho nos modos de produção capitalista. Procura-se, com isso, romper com as barreiras entre o sujeito que conhece e o objeto a ser conhecido.

Entre esses aspectos anunciados e em relação à pesquisa desenvolvida por nós com jovens em uma experiência profissionalizante, tentávamos a todo tempo não
“... fazer um isolamento entre o ato de pesquisar e o momento em que a pesquisa acontece na construção do conhecimento" pois, quando falamos “... em implicação com uma pesquisa, nos referimos ao conjunto de condições da pesquisa" (Lourau, 1993, p. 16). Um conjunto de condições, dentre algumas, foi aquela que nos levou à produção de uma escrita "fora do texto", através do diário de campo, significando, ao enfocar a nossa temporalidade no ato de pesquisar, nos envolvermos naquilo que pode ser sempre desfeito, como aponta Deleuze (1992). Não se trata de um material empírico a ser trabalhado em torno de um instrumental lógico-científico, de modo que:

O diário nos permite o conhecimento da vivência cotidiana de campo (não o 'como fazer' das normas, mas o 'como foi feito' da prática). Tal conhecimento possibilita compreender melhor as condições de produção da vida intelectual e evita a construção daquilo que chamarei 'lado mágico' ou 'ilusório' da pesquisa (fantasias, em torno da CIENTIFICIDADE, geradas pela 'asséptica' leitura dos 'resultados finais'). (Lourau, 1993, p. 77).

Como analisador das nossas implicações, o diário de campo nos permitiu reconstruir, através das memórias compactuadas com as lembranças do outro, a história das nossas trajetórias, dos lugares diversos percorridos, dos nossos encontros com os jovens, reafirmando, certamente, as relações de implicação produzidas no momento da pesquisa. Não ocupamos o lugar de especialistas, indagando sobre o que produz uma "doença", um "corpo estranho". Passamos, como analistas, a problematizar as linhas de segmentaridade dura, as verdades cristalizadas sobre os jovens, questionando, inclusive, a formação profissional produtora de um naturalizado “modo-jovem-trabalhador". É neste sentido que a análise não consiste apenas em analisar o outro, mas a si mesmo, a todo momento, inclusive, no instante da própria intervenção (Lourau, 1993).

Para se ter um pouco a dimensão do sentido de implicação, certo dia, para além dos muros do espaço militar do Exército, por volta das 18h, desço na Estação de Madureira. Para a minha surpresa, isso já na rua Domingos Lopes onde passam algumas linhas de ônibus para Jacarepaguá, encontrei, por acaso, um dos militares do projeto. Parecendo-me surpreso também, disse-me que estava confirmado o nosso encontro para o dia 29, na próxima quinta-feira. Comentei que havia estado no Comando Militar do Leste (CML), e estava indo para casa. De fato, eu não esperava encontrá-lo. Percebi que ele gostaria de falarme algo, mas não sabia exatamente o quê. A rua em que estávamos não era o melhor lugar para conversarmos. Normalmente hipertensa pelo grande fluxo de pessoas que por lá transitam, tive a sensação de que deveria 'segurar' um pouco o meu desejo de 
chegar a casa, e escutar ou não um 'silêncio falante' que tanto o denunciava, através de seus olhos, de sua pele. (Diário de Campo, 26/07/2004).

Assim, todas as percepções, as observações, sentimentos de medo, de alegria, que experimentamos ao longo do processo da pesquisa, eram registrados em nosso diário que, em fragmentos feito memória, nos permitia analisar, em um certo sentido, tal lógica pensada por Walter Benjamin (1994) ao se referir às noções de linguagem e de experiência. Ao recolhermos alguns fios do diário, desejamos colocar em foco também em que medida nos implicamos no presente estudo em um determinado espaço institucional.

Talvez o diário (e outros dispositivos inventados ou a inventar) possa auxiliar a produzir outro tipo de intelectual: não mais o orgânico (ou de partido), de Gramsci; nem o engajado, de Sartre (que, muitas vezes, parece se esquecer de analisar as implicações de seu 'engajamento'); mas o IMPLICADO (cujo projeto político inclui transformar a si e a seu lugar social, a partir de estratégias de coletivização das experiências e análises). (Lourau, 1993, p. 85).

Nessa perspectiva, e a partir do dispositivo-encontro, buscamos construir com os jovens um modo de pesquisar, no projeto de formação profissional, em que deixávamos de ser indivíduos, para tentarmos estabelecer alguns fios das nossas histórias, com toda a carga que nos atravessa de emoções, de desejos, de insegurança, etc. Aqui, a noção de dispositivo corresponde a uma situação produzida em um instante da pesquisa objetivando produzir determinadas falas, atitudes, comportamentos, que, no espaço instituído são mediados por atitudes normatizadas. Conforme assinala Deleuze (1990, p. 156), “... implica líneas de fuerzas . . . operan idas y venidas, desde el ver al decir e inversamente, actuando como flechas que no cesan de penetrar las cosas y las palabras . . .” Nessa dimensão onde as palavras são movimentos:

... Vozes se cruzam afirmando a existência do dicionário. Um jovem se levantou, foi até uma pequena estante ao fundo da sala e começou a procurar a palavra. Aqui a dispersão começou. Alguns começaram a brincar, tirar a atenção de outro colega, jogando papel etc. Diante da agitação, do barulho, fiquei pensando comigo mesmo: e agora, o que devo fazer? Usar de uma possível ordem inútil, acreditando que a tenha? Será que o militar vai ouvir e chegará em breve para impor a sua ordem instituída, fazendo valer a sua autoridade? Que códigos devo utilizar? Da psicologia? Sei que há vários, mas aqui não é o momento. Tenho, inclusive, dúvidas quanto à sua aplicabilidade. Não quero ficar atrás das técnicas da ciência. Tudo é novo para mim e para eles. (Diário de Campo, 21/05/2004).

O fragmento acima traduz, certamente, que estávamos ali para questionar a nós e ao projeto, como já menci- onado. Passamos a produzir, a partir da reinvenção de cada encontro, uma mútua revelação no olhar que, muitas vezes, expressava aceitação e resistência, cumplicidade e desconfiança. Éramos, na dilatação dos olhares e no lampejo das palavras, observados e observávamos.

. . . Não quero ser associado a um instrumento de disciplina, de controle. Ao contrário, entendo o contato com os jovens como uma multiplicidade de movimentos que pode fazer emergir um território existencial não mais da 'ordem indivíduo', mas do coletivo (Diário de Campo, 21/05/2004).

Como em uma relação onde o homem se faz fazendo o mundo, e se constitui como sujeito se fazendo na linguagem, na coletividade (Benjamin, 1994).

Assim, as falas e os silêncios, às vezes "soltos no tempo", dos jovens, dos educadores e dos militares, chegavam até nós de forma direta e indireta. Pretendíamos, por meio do diário, romper com a lógica do que é perguntado e o que se pode responder. Sair do campo das certezas, das entrevistas prontas, de questões previamente já respondidas a partir de suas formulações. Ressaltamos que, nos encontros, não utilizamos de atividades previamente determinadas por nós, constituídas por modelos prévios. Realizamos apenas uma oficina onde pretendíamos dialogar a partir da narrativa do olhar sobre algumas fotografias de Sebastião Salgado, tendo como pano de fundo o jovem no cotidiano da miséria, da guerra. Entendíamos que esse material poderia se constituir em ferramenta para pensar. Sendo assim, optamos pela emergência de cada encontro percebido como único e produtor de muitos sentidos. Se a tônica era suscitar diálogos com os jovens, fazê-los falar por si, ousamos através do bricoleurs refazer outros espaços em um lugar instituído, militarizado. Como não há uma tradução exata para o português, bricolage pode significar o aproveitamento de coisas usadas, danificadas e adaptadas para outras funções. Portanto, trata-se “ ... sempre de libertar a vida lá onde ela é prisioneira ...” (Deleuze \& Guattari, 1992, p. 222).

Lembro-me que no primeiro encontro, já havia queixa de um educador sobre comportamentos e atitudes apresentados por alguns jovens. Ou seja, é como se o psicólogo tivesse o poder da cura. Lembro-me, mais uma vez, do sentimento de desassossego que surge diante de cada enfrentamento novo vivido por mim. Com formação em psicologia e diante da constituição de um determinado tecido social onde cada sujeito corresponde a um lugar e, cada lugar, um sujeito, deveria dar conta de possíveis 'anormalidades'. Acreditava que diante da certeza e do suposto conhecido, era preciso produzir novos fatos. Para o educador, se algum jovem apresentasse um comportamento 'anormal', deveria ser medicalizado para, em seguida, tornado 'obediente', integrar-se às atividades. Pude perceber também que essa leitura se fazia presente no texto do tenente. Sendo assim, foi a par- 
tir dessas constatações que resolvi colocar um pouco 'às claras' o que, efetivamente, objetivava realizar neste espaço. (Diário de Campo, 06/05/2004).

Sendo assim e a partir deste contexto, a pesquisaintervenção representou mais uma ferramenta de trabalho. Optávamos por esta ferramenta para que pudéssemos nos tornar cada vez mais implicados com outras formas de leituras da realidade e da vida. Era uma pesquisa sendo produzida com o corpo todo, que recusa o conformismo, já posto, e que deseja produzir outros movimentos. Uma pesquisa-intervenção que implica o corpo implicado. Uma intervenção que, como procedimento de aproximação com o campo, “... mostra-nos que ambos - pesquisador e pesquisado, ou seja, sujeito e objeto do conhecimento - se constituem no mesmo tempo, no mesmo processo" (Barros, 1994, p. 308).

Com as nossas diferenças, fomos nos complementando e nos diferenciando, na arena de múltiplas vozes, onde as escutas, as falas em silêncio, nos colocavam em conflito com o que os jovens diziam, com o que nós dizíamos, na intimidade, na cumplicidade. Assim como Deleuze pensa o devir, as linhas de fuga, acreditávamos que poderíamos ressignificar sentidos postos em suas vidas e pelas práticas de formação profissional naquele espaço instituído. A pesquisa-intervenção representou um caminho metodológico, ao possibilitar a análise dos sentidos que diferentes sujeitos atribuem aos jovens, assim como os sentidos que os jovens atribuem ao espaço do projeto. Colocar em análise esse projeto que produzia uma realidade sócio-política, através de uma prática educativa, era o nosso "objeto", mesmo diante dos desafios que atravessavam um modo sensível de pesquisar, e ora traduzido no fragmento seguinte:

... Mas não é fácil. Que dificuldade! Como querer controlar o barulho da vida de tão jovens sujeitos? Fiquei alguns segundos em contato com a minha inutilidade até o momento que um jovem falou bem próximo: 'anota os nomes no caderno'. Olhei para ele e sorri. Sabia que eu não estava ali para controlá-los. Tentei devolver ao barulho da maioria com o meu silêncio. Tentei experimentar e sentir que existe um outro e de que eu também sou o outro. O barulho não me incomodava. Não deveria provocar fragmentos naquela vibração de vozes. Havia uma energia nos jovens, isso é óbvio. É preciso acolher essas vibrações. (Diário de Campo, 21/05/2004).

Nessas possibilidades múltiplas, construímos encontros, a partir do diálogo com os jovens, em que a questão da democracia, do confronto de idéias, de opiniões, do sentido de experiência, pudesse ser partilhado, narrado e coletivizado. Entendíamos que o sentido de uma experiência entre os jovens poderia ter algum ponto de interseção com a história de todos. Eram encontros semanais iniciados em maio de 2004, com término em dezembro do mesmo ano. Além desses aspectos e pensando a partir dos registros de diferentes vidas que vão compondo os vários mosaicos de nossa existência:

Lembro-me que partimos para falar um pouco do cotidiano de cada um, inclusive, sobre o meu. Indagados sobre a possibilidade de terem recebido algum assédio por parte do tráfico para fazer uso de drogas ou mesmo para trabalhar, a maioria respondeu que sim. Inclusive, apontaram que o assédio é mais sedutor quando surge das 'garotas', segundo mencionaram. Sedutor porque haveria a possibilidade caso aceitassem o convite, de transar com as 'garotas'. A maioria afirmou que já tinha passado por tal situação, mas que negaram. O motivo da negação foi que pensaram primeiro nas suas mães. Devem resistir a qualquer tipo de envolvimento com a vida do crime. Por outro lado, um jovem, embora não tenha afirmado enfaticamente seu suposto envolvimento no tráfico, parece-me que a sua possível participação se dá de maneira indireta, segundo mencionou, jocosamente, um outro jovem. 'Professor, esse moleque aqui tem um pai que é rico. Ele é dono de Antares'. Antares? Perguntei. Em seguida, respondeu o jovem: 'é uma comunidade que fica em Santa Cruz'. Nesse momento, todos os colegas mergulharam no riso. Pondo os dilemas e possíveis verdades à parte, relataram que é expressivo o número de amigos ou conhecidos que estão envolvidos no tráfico de drogas, tanto aqueles que fazem uso quanto os que efetivamente trabalham para o mercado de vendas de drogas. Os números frios da matemática contabilizam quarenta e quatro jovens envolvidos com o tráfico, conforme suposto levantamento evidenciado por eles. Confronto entre facções do mercado de tráfico de drogas é freqüente na minha comunidade, afirmou um jovem, morador de Miguel Couto, Nova Iguaçu. (Diário de Campo, 16/07/2004).

Nesse movimento de aproximação e de constante descoberta, falávamos, como mencionamos anteriormente, suscitando diálogos a partir do conceito de experiência de Walter Benjamin (1994). Era esse aspecto coletivo que buscávamos no nosso trabalho com os jovens construir o tempo todo de modo que:

Antes de reiniciarmos o acordo de trabalho, quis saber como tinha sido o encontro passado para eles e como tinha sido para mim também. Realmente, para mim foi surpresa pois percebi que eles queriam dizer algo para além do encontro, mas que tinha a ver com o encontro. A sensação que eu tive era como se todos quisessem falar ao mesmo tempo. $\mathrm{E}$ foi isso que aconteceu. Pensei então em organizar as falas. Não por inscrição. Nada disso. Tentei não interferir no movimento que estava sendo novo para eles, e para mim também. Poder falar e ser escutado por eles mesmos e por todos. Tentar captar o ritmo da percepção de todos que é o ritmo da vida, isso sim, faz sentido. (Diário de Campo, 28/05/2004). 
Pretendíamos romper, no diálogo das palavras, com as "verdades" inscritas sobre os jovens participantes do projeto como descrito no seguinte fragmento:

Mesmo do lado de fora, não tinha prestado atenção que a professora estava dentro da sala. Em seguida, ao sair da sala, ela vem em minha direção para acrescentar algo mais do que o militar já havia dito. Nesse momento, encontrava-se, ao meu lado, um jovem que estava aguardando o militar. Sou tomado de súbito por ela que me chama ao lado para dizer-me que eles não são fáceis . . . Fico pensando aqui, o quanto de implicação o seu discurso tem nas suas ações. Permanecendo no campo do confronto, da negação, é como se ela não permitisse que a potência que cada jovem tem fosse evidenciada, liberada, e, assim, ele pudesse ser sujeito de uma outra vida, de uma outra história. (Diário de Campo, 18/06/2004).

Nesse desejo pelas "rupturas como laços", reafirmávamos a existência de uma outra temporalidade, na perspectiva benjaminiana, e de um devir deuleziano que, em ambos, não é a história dos sujeitos portadores de uma virtualidade perigosa. Ao tomar emprestada essa expressão de Paul Claudel, Célia Linhares (2001, p. 28) propõe, a partir das rupturas como laços, pensar as práticas educativas e pedagogicamente instituídas como um campo de forças onde outras experiências possam se fazer instituintes. Nesta perspectiva de sentir a vida, acreditávamos que podíamos, junto com os jovens, pensar pela curiosidade, pela dúvida, pelas incertezas, em um espaço que produz um "modo-jovem-trabalhador". Afirma a referida autora que esses " ... laços carregam, intrinsecamente soldados, prazer e risco, passado e futuro, realidade e ficção", e certamente imbricados em novas rupturas, pois não éramos os sujeitos da clínica, sujeitos de uma pretensa neutralidade científica, decidimos por uma trajetória onde:

Foi necessário esclarecer, desde logo, algumas questões junto à coordenação. Coloquei para o militar que não viria fazer um trabalho clínico, de atendimento, de orientação, mas que estaria ali como um pesquisador e também como pessoa. Não como um profissional da psicologia para consertar possíveis engrenagens dos sujeitos que estariam precisando trocar as 'peças'. Claro que não falei assim. Mas fica o sentido de que frente a algum comportamento que destoa da 'normalidade', o mesmo necessita ser medicalizado, de imediato. Acredito que o militar tenha compreendido, até porque outras expectativas mesmo que sejam pensadas, não representam necessariamente o que eu venha a desenvolver com os jovens no estabelecimento. (Diário de Campo, 06/05/2004).

Enfim, na tentativa para analisar os sentidos que os jovens atribuem à formação profissional, optamos por estabelecer travessias para que eles pudessem expressar seus desejos, anseios, projetos de vida etc., inclusive, possibilitando ressignificar o próprio espaço de formação profissionalizante em suas vidas, na medida que tentávamos entender como o jovem se coloca diante de si e diante dos outros.

Ressaltamos, inclusive, que paralelo aos encontros com os jovens, realizamos, além dos registros e anotações em diário, das pesquisas documentais sobre a emergência do projeto profissionalizante, algumas entrevistas gravadas em fita cassete com a permissão de dois educadores e com o primeiro coordenador do programa na unidade militar e, em seguida, transcritas, digitadas, relidas e analisadas. Na época da pesquisa, tentamos entrevistar o atual coordenador, via aparelho eletrônico, em que, inclusive, foi perguntado se o mesmo aceitaria que a entrevista fosse gravada. Como o coordenador não concordou com o uso do instrumento eletrônico, realizamos a nossa conversa apenas com os registros, as anotações em caderno.

Em síntese, entendemos que a análise de implicação de todo material que ora produzimos, a partir do recorte pertinente para o referido trabalho, se constitui em um processo infinito, de múltiplos olhares e dizeres, certamente, quando nos deparamos com um projeto de formação profissional tão complexo e controvertido, com seus modelos universais, naturalizados na vida social dos jovens e na dos militares também, pautado em um especialismo científico, traduzido, certamente, em instrumentais teóricos e técnicos a serem aplicados pelos educadores e pelos militares no projeto, a partir de sua lógica de poder.

\section{Notas}

1. Esta tese foi orientada pela prof ${ }^{a}$. dra . Cecília Maria Bouças Coimbra no período de 2003 a 2007.

\section{Referências}

Barros, R. D. B. (1994). Grupo: A afirmação de um simulacro. Tese de Doutorado não-publicada, Pontifícia Universidade Católica de São Paulo, SP.

Benjamin, W. (1994). Obras escolhidas: Vol. 1. Magia e técnica, arte e política (7. ed.). São Paulo, SP: Brasiliense.

Coimbra, C. M. B. (1995). Os caminhos de Lapassade e da análise institucional: Uma empresa possível? Revista do Departamento de Psicologia, UFF, 7(1), 52-80.

Coimbra, C. M. B., \& Neves, C. A. B. (2002). Potentes misturas, estranhas poeiras: Desassossegos de uma pesquisa. In M. L. Nascimento. (Ed.), Pivetes. A produção de infância desiguais. Rio de Janeiro, RJ: Oficina da Arte.

Collinson, D. (2004). 50 Grandes Filósofos. Da Grécia Antiga ao Século XX. São Paulo, SP: Contexto.

Deleuze, G. (1990). ¿Que és un dispositivo? In Michel Foucault: Filósofo. Barcelona, España: Gedisa.

Deleuze, G. (1992). Conversações. Rio de Janeiro, RJ: Ed. 34.

Deleuze, G., \& Foucault, M. (1990). Os intelectuais e o poder. In 
M. Foucault. Microfísica do poder (9. ed.). Rio de Janeiro, RJ: Graal.

Deleuze, G., \& Guattari, F. (1992). O que éfilosofia. São Paulo, SP: Ed. 34.

Deleuze, G., \& Parnet, C. (1998). Diálogos. São Paulo, SP: Escuta.

Descartes, R. (1975). Discurso sobre o método. São Paulo, SP: Hemus.

Foucault, M. (1974). As verdades e as formas jurídicas. (1974). Cadernos da PUC-Rio, Conferências I e II.

Foucault, M. (1990). Microfísica do poder. (9. ed.). Rio de Janeiro, RJ: Graal.

Freire, P. (1998). Pedagogia da esperança: Um reencontro com a pedagogia do oprimido (5. ed.). Rio de Janeiro, RJ: Paz e Terra

Guattari, F. (2003). As três ecologias (14. ed.). Campinas, SP: Papirus.

Japiassu, H. (1975). O mito da neutralidade científica. Rio de Janeiro, RJ: Imago.

Linhares, C. (2001). Pesquisas educacionais podem romper com profecias de nascimento? Memórias e projetos do magistério no Brasil. In C. Linhares, I. Fazenda \& V. Trindade (Eds.), Os lugares dos sujeitos na pesquisa educacional (2. ed.). Campo Grande, MS: Editora da Universidade Federal do Mato Grosso do Sul.

Lins, D. (2001). Sujeitos e devires: O corpo-drogado. In D. Lins (Ed.), Nietzsche e Deleuze: Pensamento nômade. Rio de Janeiro, RJ: Relume Dumará.

Lourau, R. (1993). Análise institucional e práticas de pesquisa. Rio de Janeiro, RJ: Editora da Universidade Estadual do Rio de Janeiro.

Machado, R. (1981). Ciência e saber. A trajetória da arqueologia de Foucault (2. ed.). Rio de Janeiro, RJ: Graal.

Paulon, S. M. (2005, set.-dez.). A análise de implicação como ferramenta na pesquisa-intervenção. Psicologia e Sociedade, 17(3), $18-25$.

Pelbart, PP. (2003). Vida capital. Ensaios de biopolítica. São Paulo, SP: Iluminuras.

Pessoa, F. (2006). O guardador de rebanhos e outros poemas. Poesia completa de Alberto Caeiro. São Paulo, SP: Landy.

Santos, B. S. (1999). Um discurso sobre as ciências (9. ed.) Porto, Portugal: Afrontamento.

Eduardo Antonio de Pontes Costa é Psicólogo pela Universidade Federal da Paraíba, Mestre em Saúde Pública pela Fundação Oswaldo Cruz, Doutor em Educação pela Universidade Federal Fluminense (UFF) e Professor Substituto do Departamento Sociedade, Educação e Conhecimento, da Faculdade de Educação, da UFF. Endereço para correspondência: Rua Grapiúna, 29, Vila Valqueire, Rio de Janeiro, RJ, 21330 - 250. eduapcosta@bol.com.br

Cecília Maria Bouças Coimbra é Psicóloga, Professora Adjunta da UFF, Doutora em Psicologia pela Universidade de São Paulo. Fundadora e atual presidente do Grupo Tortura Nunca Mais/RJ e Conselheira do Conselho Regional de Psicologia do Rio de Janeiro. Endereço para correspondência: Praia de Botafogo, 22, Apto. 502, Botafogo, Rio de Janeiro, RJ, 22 250-014. gtnm@alternex.com.br

\section{Nem Criadores, Nem Criaturas: Éramos todos Devires na} Produção de Diferentes Saberes

Eduardo Antonio de Pontes Costa e Cecília Maria Bouças Coimbra

Recebido: 13/06/2007

$1^{\mathrm{a}}$ revisão: $15 / 10 / 2007$

Aceite final: 14/11/2007 